\title{
Científicos Argentinos y su lucha contra la fiebre hemorrágica argentina, 1963-1990
}

\section{Argentine scientists and their struggle against the Argentine hemorrhagic fever, 1963-1990}

GRACIELA AGNESE

Pontificia Universidad Católica Argentina | UCA

RESUMEN Desde inicios de la década del '50 se reiteraban en el Noroeste de la provincia de Buenos Aires (Argentina) brotes epidémicos de una extraña enfermedad. La nueva virosis afectaba al hombre de campo.Y, fue denominada como fiebre hemorrágica argentina (FHA). En esta ponencia centramos nuestra mirada en las características y los logros de los distintos equipos científicos que intervinieron en la problemática de la FHA durante el período 1963-1990, etapa que culminó con el desarrollo de una vacuna que permitiría controlar la enfermedad. También consideramos el contexto socio-histórico y económico y el rol desempeñado por el Estado como factores que pudieron tensionar la labor de los investigadores abocados al estudio de la virosis hemorrágica.

Palabras clave fiebre hemorrágica argentina - científicos - vacuna - Estado

\begin{abstract}
Since the beginning of the '50s were reiterated in the Northwest of the province of Buenos Aires (Argentine) a strange disease outbreaks. The new viruses affected the field man. And it was called as Argentine hemorrhagic fever (AHF). In this paper focus our gaze on the characteristics and achievements of the different scientific teams involved in the problem of the AHF during the period 1963-1990, stage which culminated in the development of a vaccine that would make it possible to control the disease. We also consider the socio-historical and economic context and the role played by the State as factors that could stress the work of the researchers involved in the study of the hemorrhagic viruses.
\end{abstract}

Key words Argentine hemorrhagic fever - scientists - vaccine - State

\section{Introducción}

Desde inicios de la década del '50 se reiteraban en el Noroeste de la provincia de Buenos Aires brotes epidémicos de una extraña enfermedad que presentaba síntomas análogos a los de la gripe. La nueva virosis, afectaba al hombre de campo en tiempos de cosecha en áreas de la Pampa Húmeda, siendo ésta la región más rica de la Argentina y de la cual dependía su economía sustentada en el modelo agro-exportador.

La nueva enfermedad fue denominada como fiebre hemorrágica argentina (FHA). ${ }^{1}$ Y, conocida popularmente como "mal de los rastrojos" pues es en el rastrojo del maíz donde se encontraban los nidos de las lauchas transmisoras de esta virosis. El Estado nacional - Arturo Frondizi en la presidencia - como provincial - Oscar Allende en la gobernación de 
la provincia de Buenos Aires - reconoció a esta enfermedad como un problema sanitario de importancia a partir de 1958, al producirse una epidemia con epicentro en la pequeña localidad de 0'Higgins (NO Bonaerense) con un elevado índice de mortalidad que osciló entre un 18 a un 19,43\% sobre un total de 260 a 265 enfermos. ${ }^{2}$

Las autoridades sanitarias impulsaron diversas medidas, entre las que destacan la conformación de equipos científicos. El Ministerio de Salud de la Nación designó a la Comisión Nacional Ad Hoc presidida por el Dr. Ignacio Pirosky, director del Instituto Nacional de Microbiología (Malbrán), e integrada por investigadores del mencionado Instituto; ${ }^{3}$ y, el Ministerio de Salud Provincial, la Comisión de Estudio de la Epidemia del Noroeste Bonaerense. También organizó un equipo, luego de recibir una convocatoria de médicos de Junín, el virólogo Armando Parodi, de la Cátedra de Microbiología y Parasitología de la Universidad de Buenos Aires (UBA), junto con el Dr. Humberto Rugiero, de la Cátedra de Enfermedad Infecciosas. Este grupo fue conocido como Comisión de la Facultad de Medicina de la UBA. ${ }^{4}$

Mientras la Comisión de la provincia de Buenos Aires se dedicó a la prevención y atención de los enfermos, los equipos liderados por Parodi y Pirosky se ocuparon de la investigación científica. Ambos investigadores se habían formado en el modelo impulsado por el Dr. Bernardo Houssay, centrado en la investigación experimental con hincapié en las ciencias básicas, la búsqueda de la excelencia siguiendo los modelos de los grandes centros mundiales, sólida y disciplinada organización institucional, actitud experimentalista, difusión de los resultados mediante la publicación en revistas internacionales y carrera investigativa con modalidad de dedicación exclusiva. ${ }^{5}$

Las dos comisiones, sin coordinación y con una gran competitividad, en pocos meses de trabajo, durante 1958, lograron aislar el virus Junín - agente etiológico de la enfermedad -, entre otros importantes avances. El aislamiento del virus causal de la enfermedad posibilitó al equipo liderado por el Dr. Ignacio Pirosky desarrollar una vacuna contra la FHA; proyecto que quedó trunco al producirse el derrocamiento del presidente Arturo Frondizi en marzo $1962 .{ }^{6}$

En síntesis, en el período 1958-1962 destacan, en el campo científico de la fiebre hemorrágica, la denominada Comisión Nacional Ad Hoc liderada por el Dr. Ignacio Pirosky, con sede en el Instituto Malbrán, y la Comisión de la Facultad de Medicina de la UBA dirigida por el Dr. Armando Parodi.

A partir de 1963 la fiebre hemorrágica comenzó a extenderse a nuevas áreas geográficas (ver mapa al final del artículo) determinando la intervención de nuevos grupos e instituciones científicas. Nos proponemos centrar nuestra mirada en los equipos científicos que destacarán por sus logros en el campo de la FHA durante el período 19631990: el grupo surgido en el Instituto Malbrán, el equipo dirigido por Parodi y el centro de Pergamino que liderará el Dr. Maiztegui. Nos interesan sus características, condiciones de trabajo y logros, particularmente los proyectos de desarrollo de una vacuna contra la enfermedad. También consideraremos el contexto socio-histórico-económico y el rol desempeñado por el Estado como factores que pudieron tensionar la labor de los investigadores abocados al estudio de la virosis hemorrágica.

\section{La epidemia se extiende, coordinación del Estado y nuevas acciones científicas 1963-1968}

Producido el golpe de Estado contra el presidente Frondizi (28 de marzo de 1962) asumió José María Guido quien presidía el Senado en un intento por mantener la ficción de un gobierno civil. En la zona afectada por la fiebre hemorrágica volvieron a surgir signos de preocupación y voces de alarma, con expresiones críticas hacia la gestión del gobierno nacional. Durante el mes de julio entidades como cooperativas agrícolas, ${ }^{7}$ la Sociedad Rural ${ }^{8}$ y particulares, con apellidos ilustres, vinculados a esta actividad (Morea, Ocampo, Pueyrredón, Blaquier), impulsados fundamentalmente por la escasez de braseros, quiénes temerosos por contraer la virosis rehusaban trasladarse a la zona epidémica, con la consecuente elevación del jornal, reclamaron al presidente por la falta de resultados de las medidas adoptadas en la lucha contra la enfermedad señalando que las víctimas que ésta producía se debían a la desaprensión de las autoridades. ${ }^{9}$ 
En 1963 la virosis hemorrágica se manifestó en el sudeste de la provincia de Córdoba, en la zona de Laboulaye determinando, por impulso del gobierno provincial, la intervención del Instituto de Virología de la Universidad Nacional de Córdoba dirigido, en ese entonces, por el Dr. José María Vanella. ${ }^{10}$ Este científico, junto con los doctores Lola González, S. Paglini y A. Márquez, recibieron una muestra de sangre de un enfermo que el Dr. Ramón Caballero, Director del Hospital de Laboulaye, había enviado en ómnibus simplemente conservada en hielo; a pesar de estas precarias condiciones la muestra resultó infectiva y pudieron aislar una cepa de virus Junín denominada Laboulaye 63. ${ }^{11}$

En el Instituto Malbrán continuaban con sus trabajos el doctor Julio Barrera Oro junto a las Dras. Sonia Klin, Zulema Martínez Segovia y Angélica Tessie, en un ambiente de pobreza donde los recursos humanos, técnicos y financieros habían disminuido verticalmente ${ }^{12}$ luego del golpe de Estado contra el presidente Frondizi que derivó en la intervención de este centro científico, la exoneración de su director el Dr. Pirosky y el desmembramiento de la Comisión Nacional abocada a la investigación de la fiebre hemorrágica.

También proseguía con sus investigaciones la Comisión de la Facultad de Medicina de la Universidad de Buenos Aires, liderada por el Dr. Parodi, que acababa de recibir una donación de 21.780 dólares del Instituto Nacional de Salud de Estados Unidos, para financiar, durante un año, el estudio del virus Junín. ${ }^{13}$

A mediados de ese año en una reunión convocada por la Asociación Argentina de Microbiología, los investigadores señalaron que en el aspecto epidemiológico había quedado demostrado el recrudecimiento de la epidemia, luego de un período estacionario pero, con una reducción notable en el número de casos mortales, ${ }^{14}$ circunstancias que indicaban los progresos realizados en orden a la prevención y al tratamiento. Desde fines de 1958, por iniciativa de los Dres. Alberto Cintora y Clemente Magnoni en el Centro de Prevención y tratamiento que funcionaba en el Hospital de Junín ${ }^{15}$ - zona epidémica -, se utilizaba como tratamiento para la virosis la transfusión de plasma de convaleciente..$^{16}$ Como los resultados fueron alentadores el método fue difundido en toda la zona afectada por los miembros del equipo, en mesas redondas, conferencias, jornadas y congresos. Asimismo los médicos nucleados en este centro, como la Comisión que dependía de la provincia de Buenos Aires, implementaron campañas de prevención insistiendo, fundamentalmente, en la consulta precoz con el médico. Así esta conducta, rápidamente adoptada por la población epidémica, y el hallazgo del tratamiento específico lograron disminuir el índice de mortalidad: en 1959 de un 19,4\% había descendido a un 6,36\%. ${ }^{17}$ Sin embargo el tratamiento con plasma era objeto de cuestionamientos por falta de rigurosidad científica pues si bien existía la corroboración de su validez en modelo experimental (Grupo Parodi, 1961), no había sido testado científicamente en humanos. Ocurría, además, que se transfundía plasma no controlado existiendo el riesgo de transmitir al paciente otras enfermedades. ${ }^{18}$

Durante el desarrollo del $7^{\circ}$ Congreso de Medicina Tropical en Río de Janeiro, desde el $1^{\circ}$ hasta el 11 de septiembre de 1963, la fiebre hemorrágica argentina entró en un debate mundial, destacando la cantidad de trabajos que expusieron los miembros de la Comisión de la Facultad de Medicina de la Universidad de Buenos Aires. ${ }^{19}$

En las elecciones del 7 de julio del '63, con un debilitado sistema político y el Peronismo proscripto, resultó electo presidente Arturo Illia, candidato de la Unión Cívica Radical (UCR) del Pueblo, quien debió gobernar con la tutela de las Fuerzas Armadas y una activa oposición de todas las fuerzas políticas, particularmente del Peronismo.

En 1964 un nuevo e intenso brote señaló el recrudecimiento de la virosis hemorrágica. El gobernador de la provincia de Buenos Aires, Dr. Anselmo Marini, y su Ministro de Salud Pública, Dr. Abelardo Costa, anunciaron el envío de distintos elementos como heladeras para conservar el plasma, la contratación de médicos para atender a los pacientes del área epidémica, la edición de folletos y afiches preventivos y la centralización de las tareas de asistencia en Bahía Blanca, estableciendo en la cabecera de los distritos más afectados bancos de sangre y suministro de medicamentos. ${ }^{20}$ El Secretario de Salud, por su parte, se hizo presente en las zonas afectadas, presidiendo una Mesa Redonda sobre la enfermedad en Junín, el 11 de abril, en reuniones de representantes comunales y facultativos de la zona, como en Balcarce, el 6 de junio, y visitando Salto para inspeccionar a los hospitales del Partido.

Además, fue en este año cuando se produjo la irrupción de la fiebre hemorrágica en el Partido de Pergamino significando la aparición de una nueva zona epidémica en la provincia de Buenos Aires. A fines de Junio se habían 
contabilizado 1461 internados con 69 víctimas fatales. Así, este brote se había convertido en el de mayor número de casos, $3.427^{21}$ en total. Al mismo tiempo, era el de menor mortalidad, tan sólo un 3\%, cifra que volvía a señalar la adopción de la conducta preventiva de consulta precoz con el médico ante los primeros síntomas y, también, la eficacia del tratamiento específico (plasma de convaleciente).

Particularmente activas se mostraron las autoridades locales. Así, el Concejo Deliberante, en los primeros días de marzo impulsó la creación de una Comisión que debía elaborar un Plan de Lucha contra la virosis conformada por médicos del Hospital y concejales y, una Comisión Municipal pro fondos con el objetivo de destinar recursos al Hospital San José donde se atendía a los enfermos virósico-hemorrágicos. Estos mismos concejales, promoviendo la donación de sangre, se hicieron presentes en el Hospital para, ellos mismos, asumir esta conducta. Y, destinaron fondos para la Comisión creada para tal fin. Las autoridades municipales, vehiculizaron la formación de las comisiones antes mencionadas, y se preocuparon por gestionar de parte de la provincia el envío de medicamentos necesarios. Estas iniciativas y preocupaciones encontrarían su corolario a fines del '64 con la habilitación, en el Hospital Municipal, de un pabellón destinados a los enfermos de FHA. Al mismo tiempo, la provincia dio respuesta favorable a esta solicitud; y, el Ministro de Salud se hizo presente en Pergamino, como lo había hecho en otros partidos afectados. La Inspección de Enseñanza primaria - del Partido de Pergamino - dispuso el dictado de clases para divulgar conocimientos sobre la enfermedad. También, el gobierno provincial se ocupaba de la distribución de afiches insistiendo en la consulta con el médico ante los primeros malestares y promoviendo la donación de sangre. Asimismo continuó impulsando la realización de mesas redondas que nucleaban a autoridades sanitarias y médicos locales.

El diario La Razón denunciaba el impacto económico de la enfermedad. ${ }^{22}$ Los brotes epidémicos habían activado la elevación del jornal del peón golondrina que se negaba a trasladarse, para levantar la cosecha, desde las provincias de origen ${ }^{23}$ hacia la zona epidémica por temor a contraer la enfermedad. La virosis, además, era imputable como accidente de trabajo desde 1961, circunstancia que ocasionaba pérdidas a las compañías aseguradoras por el pago de las pólizas.

El Presidente Illia, en la apertura de las sesiones ordinarias en el Congreso Nacional, el $1^{\circ}$ de mayo de 1964, hizo referencia a la problemática de esta enfermedad expresando que:

(...) no podemos pasar por alto el problema de la fiebre hemorrágica [...], cuyo recrudecimiento y extensión en la provincia de Buenos Aires ha hecho necesario tomar medidas tendientes para actualizar la investigación de esta grave virosis. ${ }^{24}$

El 19 de mayo el Poder Ejecutivo Nacional reglamentó la notificación obligatoria de los casos de enfermedades transmisibles ocurridos en el país. La virosis hemorrágica se encontraba comprendida entre las enfermedades de registro, es decir, aquéllas de notificación con diagnóstico confirmado y que requerían la individualización de los casos utilizando con este fin un formulario estandarizado en el que debían registrarse los datos personales del enfermo incluyendo profesión y lugar donde había contraído la enfermedad. Esto permitía contar con una valiosa e imprescindible información.

En el mes de junio, con el brote en pleno desarrollo, el Presidente de la Nación resolvió la creación de la Comisión Nacional Coordinadora para el Estudio y Lucha contra la fiebre hemorrágica argentina, según decreto n. 4.299 del día 10. Este organismo, con sede en el Ministerio de Asistencia Social y Salud Pública de la Nación, había sido creado con el objetivo de coordinar y promover los trabajos de investigación que se llevaban a cabo en nuestro país. Estaba constituida por representantes de los Ministerios de Salud nacional y provinciales donde se detectara la enfermedad (Buenos Aires y Córdoba en principio), del Instituto Nacional Carlos G. Malbrán, de la Secretaría de Agricultura y Ganadería de la Nación mediante el Instituto Nacional de Tecnología Agropecuaria (INTA) y la Dirección de Servicios de Luchas Sanitarias de Agricultura (SELSA), y los profesores titulares de las cátedras en las que se estaban desarrollando investigaciones sobre la virosis. ${ }^{25}$

Según testimonios de los investigadores la creación de la Comisión fue un hito en el campo científico de la fiebre hemorrágica pues por primera vez se coordinaban los trabajos de investigación asegurando el intercambio de información 
y resultados entre los distintos grupos, acciones que hasta el momento se habían caracterizado por la competitividad y el hermetismo. ${ }^{26}$

Paralelamente, el ministerio de la provincia de Buenos Aires anunciaba para el siguiente año una partida de 7 millones de pesos destinados exclusivamente a la lucha contra la enfermedad. ${ }^{27}$

Precisamente en 1964 un investigador en fiebre hemorrágica, como el Dr. José María Vanella, sintetizaba el impacto social de la enfermedad, que le otorgaba una relevancia que no correspondía a su impacto en términos de morbiletalidad, al expresar:

(...) con respecto a la importancia de la enfermedad como problema de Salud Pública [...] estimaciones muy pesimistas llevan el número anual de muertos por FHA en todo el país, aproximadamente a un centenar, número relativamente pequeño comparado con los mil niños que anualmente matan las diarreas estivales, en la sola Provincia de Buenos Aires. Sin embargo, la neurosis colectiva del mal de los rastrojos no tiene miras de amainar. Por ello los argentinos seguiremos durante muchos años temiéndole a la fiebre hemorrágica argentina, aunque las tasas de mortalidad por otras causas como el cáncer, enfermedades cardiovasculares, diarreas estivales o accidentes de tránsito, sean muchos más elevadas. ${ }^{28}$

El brote de 1964, además, impulsó el surgimiento de un nuevo grupo de investigación...

\section{El Centro de Estudios de FHA de Pergamino 1965...}

En los primeros meses del '64 el Dr. Bernardo Houssay señalaba las dificultades de dedicarse a la investigación científica

debido a los recursos insuficientes, el déficit de medios de trabajo y locales y la falta de Institutos de Investigación. ${ }^{29}$

Habiendo retornado a nuestro país luego de haber realizado estudios sobre clínica médica y enfermedades infecciones en la Escuela de Salud Pública de la Universidad de Harvard, el Dr. Julio Maiztegui se incorporó al Centro de Educación Médica e Investigaciones Clínicas (CEMIC) donde se vinculó con trabajos sobre la virosis hemorrágica, postulando que, para estudiar y controlar la enfermedad, debía instalarse un instituto de investigación y atención de los enfermos en la misma zona epidémica. ${ }^{30}$ Con este proyecto en mente se vinculó con el Instituto Malbrán, en ese momento dirigido por el Dr. Antonio Vilches.

Desde principios de 1965, un equipo de médicos, investigadores y técnicos del Instituto Malbrán, del Centro Piloto de Atención Médica de la Comunidad y del CEMIC se instalaron en Pergamino dando origen el Centro de Estudios para Fiebre Hemorrágica. El Dr. Barrera Oro, en el Instituto Malbrán, era el encargado de realizar el diagnóstico de laboratorio de muestras de enfermos enviadas desde Pergamino y entrenaba, en ese sentido, a personal que trabajaba en el centro dirigido por Maiztegui. ${ }^{31}$ Estos fueron los primeros vínculos, que por cierto resultarían fructíferos, entre los dos científicos. El Instituto Nacional de Tecnología Agropecuaria (INTA) colaboró a través de la Estación Experimental que funcionaba en la pequeña ciudad, cediendo espacio para la instalación de un laboratorio de virología y, el Hospital San José habilitó una sala para la atención de los enfermos. El aporte privado de la Fundación Emilio Ocampo ${ }^{32}$ permitió que, en meses, se resolvieran los problemas económicos y pudieran comenzar los trabajos.

El Dr. Vilches justificó la decisión de centrar los estudios en el Partido de Pergamino enumerando diversos factores, tanto de índole científica, dada por el hecho que la virosis se había presentado en el sur del partido, dejando libre el norte, permitiendo delimitar una zona "limpia" de una "sucia" que posibilitaba realizar adecuados estudios ecológicos y comparativos, como factores político-económicos. Entre éstos, destacó a la Fundación Ocampo, al apoyo de la Intendencia de Pergamino y de la Comisión Nacional Coordinadora. Además, señaló razones operativas pues contaban con un Hospital dotado de instrumental científico, técnico, y personal idóneo. Para, finalmente, subrayar un factor de índole social expresado en el interés de los chacareros de la zona. ${ }^{33}$ 
El índice de mortalidad en Pergamino, en 1965, era cercano al 30\%. ${ }^{34}$ El nuevo grupo científico comenzó a trabajar, en plena zona epidémica, sobre el diagnóstico, el tratamiento, la transmisión de la enfermedad, los mecanismos por los que se afecta a diversos órganos y funciones, la ecología - desarrollando estudios con roedores - y la epidemiología iniciando, en este último aspecto, un programa de vigilancia epidemiológica. Este equipo, como ya había ocurrido con el de Pirosky, disputaría a la comisión de Parodi, el liderazgo o preeminencia en orden a los logros en el campo científico vinculado con la enfermedad.

Un nuevo capítulo de gobiernos autoritarios se inició en Argentina el 28 de junio de 1966 cuando el presidente Arturo Illia fue sacado por la fuerza de su despacho. El país, profundamente dividido y polarizado, se encaminaba hacia un terreno violento que culminaría en la lucha armada.

Algunos meses después, en septiembre de 1966, la Comisión Nacional Coordinadora publicó indicando que la letalidad de la virosis oscilaba entre un 5 a un 7\%. ${ }^{35}$ La investigación clínica les permitía considerar que no siempre el diagnóstico clínico era confirmado en el laboratorio en el que se aplicaba la serología y el aislamiento del virus, sin embargo reconocían que con experiencia y buen sentido clínico el diagnóstico era coincidente en un alto porcentaje. Sin embargo, en orden a la prevención, el organismo alertaba sobre los trabajadores rurales, quienes continuaban siendo fundamentales para la cosecha, primordialmente en épocas de lluvia, población en riego que no siempre practicaban las medidas de prevención que se aconsejaban, como el uso de botas, la protección de las heridas de las manos, las buenas normas de higiene personal y la vivienda limpia a prueba de roedores.

Frente a este panorama Julio Maiztegui realizó algo de fundamental importancia en orden a la prevención: vinculó a la población afectada con el grupo de investigadores, quiénes junto al mismo Maiztegui visitaban los pueblos afectados por la epidemia dando charlas tanto a los profesionales médicos como a la población en general en escuelas, en un galpón que era utilizado por los bomberos del lugar, en cooperativas agrarias. Así, el grupo de Pergamino, desde los inicios, realizó tareas relacionadas con educación para la salud logrando vincular el trabajo científico tanto con la población afectada como con los médicos de estas poblaciones, los primeros que iban a intervenir ante un brote epidémico.

Los distintos grupos científicos, en el período 1964-1967, continuaron con sus trabajos. Son numerosas las publicaciones de la Comisión de la Facultad de Medicina de la UBA liderada por el Dr. Parodi. Así el grupo de la Cátedra de Infecciosas, a cargo del Dr. Humberto Rugiero, refería estudios sobre descripción clínica de la enfermedad, formas clínicas, diagnóstico, laboratorio clínico, período de incubación e invasión, inoculación accidental y consideraciones médico-legales y fisiopatología de la enfermedad, entre otros. ${ }^{36}$ Publicaciones realizadas en reiteradas ocasiones con los médicos del Centro de Prevención y tratamiento de Junín. Asimismo el Dr. Parodi, con su equipo, desde la Cátedra de Microbiología y Parasitología, publicaba trabajos sobre etiología, inmunización de cobayo contra el virus Junín por inoculación del virus Tacaribe, viremia en enfermos hemorrágicos, inoculación en cobayos con virus Junín inactivado y estudios serológicos. ${ }^{37}$ Trabajos materializados con subsidios del Instituto Nacional de Salud de Estados Unidos, del Centro Internacional de Investigaciones para el Desarrollo de Canadá y del Consejo Nacional de Investigaciones Científicas y Técnicas (CONICET), ${ }^{38}$ ya que varios integrantes de la Cátedra eran miembros de la Carrera del Investigador. En 1967 la Academia Nacional de Medicina distinguió el trabajo de Mercedes Weissenbacher sobre Acción de los inmunosueros en la fiebre hemorrágica experimental con el premio Colonización Judía en la República Argentina - Subpremio estímulo anual. ${ }^{39}$ Entretanto, en el Instituto Malbrán, Julio Barrera Oro, también miembro de la carrera del Investigador del CONICET, junto a colaboradores, realizaban estudios inmunológicos con virus Junín inactivado por formol. ${ }^{40}$

En el quehacer de estos investigadores la tragedia no estuvo ausente. Así como en 1959 Pedro Martini, del Malbrán, había muerto de fiebre hemorrágica, al adquirir la enfermedad cuando trabajaba en el desarrollo de una vacuna, en el verano de 1966-1967 el joven doctor Olaf Reiner Schumacher, recientemente egresado de la Universidad de La Plata, del equipo dirigido por el Dr. Maiztegui, murió en Pergamino víctima del mal de los rastrojos. Esto evidenciaba el riesgo potencial al que estaban expuestos los investigadores de adquirir la enfermedad al manipular material contaminado con el virus Junín: la fiebre hemorrágica había sido incorporada, en 1960, como enfermedad profesional, sin embargo el monto de la indemnización era insuficiente en el caso de incapacidad total o muerte. ${ }^{41}$ 


\section{El equipo del Dr. Parodi y la vacuna XJ Clon 3 1968-1975}

Como hemos señalado luego del golpe del '62, en la cátedra de Microbiología y Parasitología de la Facultad de Medicina de la Universidad de Buenos Aires (UBA), el grupo dirigido por Armando Parodi continuaba con sus trabajos de investigación. Y, si bien debían lidiar con la falta de recursos, la alteración del orden institucional no había afectado las tareas científicas como en el caso del grupo del Malbrán liderado por Pirosky. Armando Parodi, egresado de la Facultad de Medicina de la UBA, se había desempeñado como ayudante del Profesor Houssay en la Cátedra de Fisiología. Luego de cursar estudios en la Fundación Rockefeller comenzó, en 1958, a formar un equipo de jóvenes discípulos, dedicado a la virología, inexistente hasta ese momento en la Universidad.

Concibiendo a la difusión de los resultados en publicaciones científicas como una forma de validar los trabajos, fieles al modelo del Dr. Bernardo Houssay, numerosos artículos en las revistas Medicina, El Día Médico y la Prensa Médica, entre otras ${ }^{42}$ testimonian los estudios de este equipo sobre observaciones del curso de la enfermedad en infecciones experimentales, distintos trabajos con el virus Junín y epidemiología. Trabajos financiados por la Universidad, el CONICET y la Comisión Nacional Coordinadora.

En el ámbito mundial recién se había iniciado un importante desarrollo de la Virología con la finalización de la segunda guerra mundial. En Argentina no existía ningún espacio científico con condiciones adecuadas para desarrollar una vacuna, menos aún en el caso del virus Junín ubicado entre los patógenos más peligrosos que requiere normas de máxima bioseguridad. Al mismo tiempo, el área epidémica de la virosis hemorrágica se había extendido progresivamente en la Pampa Húmeda. Hasta 1968 se registraron 8.905 casos y las formas graves de la enfermedad se observaban en el 20 a 30\% de los enfermos que, si no recibían el tratamiento específico, evolucionaban hacia la muerte..$^{43}$ Una vacuna contra la enfermedad era la única solución; incluso había interés del Estado nacional expresado a través del Secretario de Salud Pública, Dr. Ezequiel Holmberg, quien había anunciado un premio de un millón de pesos para aquél profesional que lograra hallar una vacuna preventiva contra la virosis hemorrágica. ${ }^{44}$

Por otra parte, el logro científico de una vacuna otorgaría al grupo que lo concretara, como a cada uno de sus miembros, un sólido posicionamiento en el campo científico. Durante 1966 por una invitación obtenida por el mismo Armando Parodi, la Dra. Lucía Barcelona de Guerrero se trasladó por tres meses al Instituto Nacional de Salud de Estados Unidos, con el objetivo de que aprendiera a realizar cultivo de tejidos, ya con la idea de poder atenuar una cepa del virus Junín. Así se logro una cepa atenuada a la que denominaron XJ Clon $3 .{ }^{45}$ Armando Parodi resolvió continuar con los trabajos con el objetivo de desarrollar una vacuna. En 1968 comenzaron los ensayos en seres humanos aplicando la vacuna en siete profesionales del equipo, entre éstos los Dres. Lucía Barcelona de Guerrero, Guido Squassi, Mercedes Weissembacher y Marcelo Frigerio. ${ }^{46}$ Al observarse que era inocua se resolvió ampliar el estudio vacunando a un grupo de 64 personas de la zona epidémica.

El ano de 1969 fue del Rosariazo, sucedido por el Cordobazo, en el mes de mayo, estallidos sociales protagonizados por estudiantes y obreros, en las ciudades de Rosario y Córdoba, que protestaban contra el gobierno de facto y concluyeron violentamente, con la intervención del ejército. El 23 de junio, inesperadamente, murió el Dr. Parodi, dejando al equipo de la Facultad de Medicina de la UBA sin su guía y mentor, en pleno proceso de desarrollo y evaluación de la vacuna. El 25 de noviembre se inició un programa de vacunación voluntario que contaba con el auspicio de los Ministerios de Salud de la Provincia de Buenos Aires y de la Nación y, por la Comisión Nacional Coordinadora ${ }^{47}$ que comprendía a los partidos de Junín y Rojas (NO bonaerense). Con la colaboración de los médicos del Centro de Prevención y Tratamiento de FHA de Junín, quienes se encargaron de conseguir los voluntarios, entre mayo de 1968 y febrero de 1971, se llegó a vacunar a un total de 636 personas. ${ }^{48}$ En noviembre de 1970, durante unas Jornadas sobre Fiebre Hemorrágica celebradas en la localidad de Laboulaye, mientras los médicos del Centro de Prevención y Tratamiento de Junín auspiciaban la aplicación de la vacuna, otros investigadores señalaron la posibilidad que pudiera llevar elementos tóxicos u oncológicos. 
Estaba comprobado que la vacuna inducía la formación de anticuerpos en más del 90\% de los voluntarios. Pero ante las objeciones, el Ministerio de Salud Pública de la Nación requirió la opinión de investigadores que integraban la Comisión Nacional y de la Academia Nacional de Medicina. Ambos grupos coincidieron en que no se debía continuar inoculando a voluntarios humanos con la XJ Clon 3 debido a que la historia de pasajes de la cepa y su forma de preparación no respondían a las normas de producción de vacunas para uso humano ${ }^{49}$ conforme lo establecido por la Organización Mundial de la Salud: la cepa de la vacuna tenía un pasaje por cerebro de ratón que podía hipotéticamente arrastrar un virus oncogénico. Según el testimonio de la Dra. Mercedes Weissenbacher, quien intervino en el desarrollo de la XJ Clon3, siendo conscientes de las objeciones que podían hacerse a la vacuna, el mismo equipo había resuelto no continuar con la vacunación antes que lo resolvieron las autoridades nacionales, con el objetivo de continuar las investigaciones para desarrollar una vacuna más adecuada. En estudios realizados en voluntarios vacunados, entre 7 a 9 años después de haber recibido la XJ Clon 3 (1977-1978), se observaron anticuerpos en un 83\%, sin que hubieran desarrollado otra enfermedad a causa de la vacuna..$^{50}$

A pesar de la inestabilidad institucional y sin los recursos necesarios, en el campo científico de la fiebre hemorrágica los avances continuaron. Son numerosas las publicaciones científicas del período 1968-75 por parte de los científicos de los distintos centros en importantes revistas como: Medicina, Revista de la Sociedad Argentina de Biología, La Prensa Médica Argentina, Revista de la Asociación Médica Argentina, Revista de la Asociación Argentina de Microbiología y El Día Médico. Los recursos procedían de subsidios del CONICET, algunos eran becarios y otros eran miembros de carrera del Investigador, también de la Comisión Nacional Coordinadora para la Prevención y Lucha contra la FHA, de la Secretaría de Salud Pública de la Nación, de la UBA, algún subsidio del Instituto Nacional de Salud de Estados Unidos, y de la Fundación Emilio Ocampo.

Como hemos expresado Julio Maiztegui, en el Centro de Estudios de FHA de Pergamino, lideraba un grupo que realizaba trabajos con investigadores del Instituto Malbrán, donde continuaba con sus pesquisas el Dr. Barrera Oro junto a otros científicos, ${ }^{51}$ y del Centro de Educación Médica a Investigaciones Clínicas (CEMIC) de Buenos Aires. ${ }^{52}$ Asimismo, continuaban con sus trabajos los investigadores de las cátedras de Microbiología y Parasitología y de Enfermedades Infecciosas de la Facultad de Medicina de la Universidad de Buenos Aires. ${ }^{53}$

Un nuevo conocimiento de gran importancia tuvo lugar en 1970 cuando los Dres. María Berria y Eduardo Lascano del Instituto Nacional de Microbiología (Malbrán) lograron visualizar el virus Junín en el microscopio electrónico; así fue ubicado en el grupo Tacaribe y de Arbovirus, como había sido clasificado originariamente, pasó a Arenavirus.

También en 1971 el Dr. Maiztegui consiguió la extensión del Programa de Vigilancia epidemiológica a los once partidos comprendidos en la Zona Sanitaria IV de la provincia de Buenos Aires. En este mismo año los Dres. Marta Boxaca, Vilma Savy y 0 Giovanniello - de la Cátedra de Microbiología y Parasitología de la UBA - , obtuvieron el premio instituido por el CONICET en honor a Armando Parodi con el trabajo Células Vero persistentemente infectadas con virus Junín. ${ }^{54} \mathrm{Al}$ año siguiente, el trabajo sobre Alteraciones de la coagulación en la fiebre hemorrágica argentina, realizado en forma conjunta por el ya citado Dr. Maiztegui con los Dres. Vilches, Mandó, Schwartz, Otero y Berruti obtuvo el premio "Mariano Castex" de la Academia Nacional de Medicina. ${ }^{55}$ La mencionada Academia también premió a los Dres. Weissenbacher, Besuschio y Schmuñis, de la Cátedra de Microbiología de la UBA, otorgándoles el premio Osvaldo L Bottaro por el trabajo Interrelación virus-huésped en la infección experimental del ratón con virus Junín y otras con encefalitis. Y, a los Dres. Héctor Ruggiero, Magnoni, Cintora, Milani y Pérez Izquierdo, del Centro de Junín, les concedió el premio Colonización Judía en la República Argentina por el trabajo Tratamiento de la FHA con plasma de convaleciente. ${ }^{56}$ Con este estudio el grupo de Junín insistía en la validez del plasma como tratamiento específico. La pesquisa había consistido en realizar un estudio comparativo de tres grupos de pacientes afectados con FHA a quiénes se les había dado plasma de convaleciente entre los días 2 y 5 , a otros en los días 6,7 y 8 y, un tercer grupo que no había recibido plasma, para concluir que "la diferencia de mortalidad entre los que recibieron plasma y no recibieron [...] era estadísticamente significativa" ${ }^{57}$ Los investigadores nucleados en el centro de Pergamino insistían en su negativa de utilizar el plasma de convaleciente al considerar que no estaba debidamente probada su validez en humanos. 
Y, en el 74, en momentos de incertidumbre por el impacto que la enfermedad tenía con un brote que alcanzó los 1002 enfermos, ${ }^{58}$ el grupo de Pergamino anunciaba que habían logrado determinar el aspecto del virus Junín en tejidos y órganos humanos. Este avance científico, concretado por un trabajo conjunto entre los laboratorios de Pergamino - que realizaron los estudios clínicos y virológicos de los pacientes - la Cátedra de Patología II de la Facultad de Medicina de La Plata - que efectuó el trabajo de microscopia electrónica - y del Laboratorio de Reumatología e Inmunología del CEMIC - con el trabajo de inmunofluorescencia - tenía el valor de aclarar cómo se producía el daño en los enfermos. ${ }^{59}$

En ese mismo año, la Academia Nacional de Medicina otorgó el premio Osvaldo Bottaro a las Dras. Guillermina Help, Elsa Damonte y Sonia Brieux de la Cátedra de Microbiología de la UBA, por su trabajo sobre línea contínua de células GH 7 (M). ${ }^{60} \mathrm{Al}$ año siguiente, la misma academia, nuevamente premiaba a los Dres. Héctor A Milani, Pérez Izquierdo, Adolfo Barri, Héctor Ruggiero, Magnoni y Cintora, en este caso, por el trabajo Tratamiento de las formas nerviosas de FHA con drogas inmunosupresoras.

\section{Maiztegui, un Instituto Nacional y la vacuna Candid 1976-1990}

Con la presidencia de María Estela Martínez de Perón, quien había asumido ante el fallecimiento del presidente Perón, ocurrido el 1 de julio de 1974, el espiral de violencia en el país se agudizó; los rumores de golpe de Estado arreciaron. Finalmente, el 24 de marzo de 1976, una Junta Militar se hizo cargo del poder.

Con este gobierno militar se profundizó la represión ideológica y la persecución política sobre la sociedad toda, circunstancias de las que no quedaría exento el ámbito científico. “En junio de 1976, a tres meses del golpe de Estado militar, 52 investigadores (CONICET) fueron declarados cesantes en un solo acto [...] llegando a totalizarse, con profesionales de apoyo y técnicos también destituidos, más de cien cesantías". 61 "El país se vuelve plenamente expulsor (de "cerebros")" como consecuencia de la intolerancia política, del deterioro económico y del terrorismo de Estado". 62 Señala Osvaldo Reig que una de las principales estrategias del gobierno de facto fue la de debilitar a las universidades como centros de investigaciones impulsando, en su lugar, la concentración de gran parte de la actividad científica en institutos, centros y programas del CONICET, "se crearon institutos de excelencia verdadera, liderados por investigadores de idoneidad indiscutida, y se fundaron otros, ya sea institutos, centros o programas, para dar albergue a submediocres sin antecedentes suficientes ni respetabilidad académica alguna". ${ }^{63}$

La fiebre hemorrágica, con un índice de mortalidad del 10\%, ocupaba una superficie de $100.000 \mathrm{~km}^{2}$, con más de un millón de habitantes ${ }^{64}$ (Noroeste bonaerense, sur de las provincias de Córdoba y Santa Fe, ver mapa al final del artículo).

Las nuevas autoridades de la provincia de Buenos Aires designaron al Dr. Maiztegui como Coordinador de la IV Zona Sanitaria con sede en Pergamino Ese mismo año la Secretaría de Salud Pública y la Oficina Sanitaria Panamericana organizaron un Seminario Internacional sobre Fiebres Hemorrágicas, desde el 29 de noviembre al 3 de diciembre, coordinado por los Dres. Maiztegui, Barrera Oro y Mercedes Weissenbacher. Este encuentro científico fue precedido por un Simposio Internacional (1975) sobre Infecciones por Arenavirus organizado por la OMS debido a la reciente aparición de otras fiebres hemorrágicas, como la FH boliviana y fiebre de Lassa, registrándose también epidemias de ébola. El Seminario del '76 concluyó sosteniendo que dados todos los avances alcanzados por la comunidad cientíica argentina en el campo de la FHA, resultaba prioritario el desarrollo de una vacuna que, en el caso de esta virosis, debía ser financiada por el Estado y de acceso gratuito para la población, ya que estaba categorizada como "droga huérfana". Es decir, un producto imprescindible para una población restringida, cuyo nivel de demanda no la hacía comercialmente interesante para los laboratorios privados.

Efectivamente los avances científicos en el campo de esta enfermedad habían sido notorios pues, transcurridos 20 años desde que se reconoció a la fiebre hemorrágica argentina como entidad nosológica, los investigadores argentinos 
habían logrado aislar el agente etiológico, determinar su ubicación taxonómica, reconocer numerosas características físico-químicas y biológicas y muchos aspectos de su epidemiología. "Simultáneamente se había avanzado en el conocimiento de la enfermedad en el hombre, su diagnóstico clínico, el manejo y tratamiento de los enfermos". 65

En 1977, el gobierno nacional resolvió adoptar como propias las recomendaciones del Seminario citado. Por impulso del Capitán de Navío (RE) Adolfo Maillé - Subsecretario de Estado de Medicina y Sanitaria - se designó al equipo de Pergamino sede del Instituto Nacional de Estudios sobre Virosis Hemorrágicas. Diversos factores confluyeron en la elección de este grupo, como el posicionamiento que habían alcanzado a través de los distintos trabajos de investigación que realizaban, la circunstancia de poder erigir un centro de investigación en plena zona epidémica y la presencia del médico Maillé, formado en la cátedra de Parodi y amigo del Dr. Julio Barrera Oro. ${ }^{66}$ Este científico trabajaba con la enfermedad desde 1954, había sido miembro del equipo del Dr. Pirosky (1959-63) y, posteriormente, continuando con sus investigaciones en el Malbrán, se había vinculado con el equipo liderado por el Dr. Maiztegui.

El nuevo Instituto (1978) se convirtió además en sede de un Programa Nacional de Lucha contra la FHA que se implementó mediante convenios con las provincias afectadas por la enfermedad: Buenos Aires, Córdoba, Santa Fe y La Pampa. Este programa se proponía organizar bancos de plasma de convalecientes en lugares estratégicamente distribuidos; disponer de servicios de clínica médica en los hospitales del área epidémica; e implementar campañas de educación sobre las conductas de prevención. La creación de este nuevo organismo significó el cese en sus funciones de la Comisión Nacional Coordinadora creada en 1964.

También con el objetivo de lograr la vacuna el Gobierno Nacional suscribió el convenio ARG/78/009 con Naciones Unidas, a través de su Programa para el Desarrollo, la Oficina Sanitaria Panamericana y el Instituto de Investigaciones en Enfermedades Infecciones del Servicios de Sanidad del Ejército de Estados Unidos (USAMRII). El convenio, en el que intervenía el Instituto de Pergamino, posibilitaba enviar un especialista al USAMRII para desarrollar una vacuna; y, el gobierno argentino, se comprometía a construir en Pergamino un laboratorio de Virología de Alta Seguridad para producir la misma una vez que estuviera desarrollada. Las obras de este laboratorio, que sería el más moderno de Sudamérica, se iniciaron en octubre del '80, y se preveía la finalización para 1982. El Dr. Julio Barrera Oro, jefe del Departamento de Virus del Instituto Malbrán, fue designado para viajar Estados Unidos. Según su testimonio el ofrecimiento del ejército norteamericano fue crucial debido a que en el país no se disponía de un laboratorio con instalaciones adecuadas para manejar un virus de alta peligrosidad como el Junín; el interés norteamericano obedecía "lisa y llanamente a tener protección contra un agente de guerra bacteriológico" ${ }^{67}$ la presencia de un gobierno militar en nuestro país habría facilitado la vehiculización del convenio. En 1978 el Instituto de Pergamino contaba con un equipo de 12 personas, en 1980 ya de 48 y sobre un proyecto inicial de inversiones de 1.800 millones de dólares el gobierno llevaba empleados, para 1980, 2.600 millones.

Desde 1975 la OPS impulsó la adopción de la estrategia de atención primaria de la salud; entre los programas derivados de esta estrategia se encontraba el de la inmunización. ${ }^{68}$ En este marco se comprende el impulso de la OPS a la creación de un Instituto Nacional, paso previo para la concreción de un convenio internacional que haría posible el desarrollo de una vacuna contra la FHA.

Cuando finalizaba el año 1979 los Dres. Maiztegui, Néstor Fernández y Alba De Damilano publicaron los resultados de un estudio iniciado en el '74, con 217 pacientes, que demostraba la utilidad del Plasma de Convaleciente como tratamiento específico, estableciendo que la mortalidad del 30\% que presentaba la enfermedad se reducía al 3\% si los pacientes eran tratados con plasma de personas ya enfermas antes del octavo día de haber contraído el mal. ${ }^{69}$ Este estudio doble ciego validó el tratamiento que tantas diferencias había suscitado entre los científicos, específicamente con los médicos nucleados en el Centro de Junín, descubridores del tratamiento, pero duramente cuestionados por los investigadores del Malbrán y por Maiztegui, al haber implementado el plasma de convaleciente en forma empírica.

Al año siguiente Julio Maiztegui con colaboradores obtuvieron el subpremio Estímulo Anual otorgado por la Academia Nacional de Medicina con su trabajo Persistencia de anticuerpos inmunofluorescentes contra virus Junín. Su utilidad en el diagnóstico y tratamiento de la fiebre hemorrágica argentina. El Dr. Maiztegui, quien ya había obtenido en dos ocasiones el premio Mariano R. Castex, también de la citada Academia, dirigía a este grupo en su mayoría 
procedentes de distintos lugares del país. Así, la Dra. Alba Juárez de Damilano, farmacéutica y bioquímica egresada de la Universidad de La Plata, trabajaba en el Instituto desde 1974; Néstor Fernández, médico egresado con diploma de honor de la Universidad de Buenos Aires, se había trasladado a Pergamino en 1968; la Dra. Ana Ambrosio, bióloga graduada en la Universidad Nacional de Córdoba, había iniciado su trabajo sobre virosis hemorrágicas en el Instituto de Virología de esa universidad, continuándolos con Maiztegui desde 1977; Delia Enría, también médica, había egresado de la Universidad Nacional de Rosario y desde 1979 desarrollaba su actividad en el Instituto de Pergamino; Francisco Luis Raso, el único pergaminense, era ayudante técnico de laboratorio desde el'77. Todos aprendieron de Maiztegui la rigurosidad metodológica, la incansable laboriosidad y "la tenacidad para sostener los principios y la pelea cuando se tienen objetivos claros", ${ }^{70}$ si bien no era fácil el trabajo con este investigador caracterizado por su mal genio. Carácter que se modificaba sustancialmente frente al paciente: "cuando Maiztegui trataba a un enfermo se transformaba, le hablaba de una manera que sólo con escucharlo el paciente ya se sentía mejor".71

La Cátedra de Microbiología y Parasitología de la UBA, para la misma época (1979-1980), continuaban intentando aislar otras cepas a parte de la XJ. En el piso 11 de la Facultad de Medicina se había construido un laboratorio de Alto Riesgo. Las Dras. Lucía de Guerrero y Nora Nota reconocían las buenas condiciones de trabajo sosteniendo que la Universidad proveía toda la infraestructura, "lo que comporta una enorme erogación. Y la Secretaría de Salud Pública y Secretaría de Ciencia y Técnica nos dan su apoyo económico".72

También durante 1978 y 1979 esta misma cátedra, junto al Dr. Héctor Ruggiero y los médicos del Centro de Prevención y Tratamiento de FHA Junín, realizaron estudios a 267 personas que habían sido inoculados con la vacuna XJ Clon 3 observando anticuerpos en un 83\% de los mismos, sin que hubieran desarrollado otra enfermedad a causa de la vacuna. ${ }^{73}$

A fines de 1980, las conclusiones de las I Reunión Anual del Programa Nacional de Lucha contra la FHA, realizada en Villa Cañás (Santa Fe), señalaron que durante 1978, '79 y '80 se había registrado una disminución progresiva en el número de casos y merced a la valiosa colaboración de los médicos tratantes y de los funcionarios provinciales del Programa se estaba logrando la vigilancia epidemiológica de la enfermedad. ${ }^{74}$

En una entrevista realizada en 1981 Julio Maiztegui reconocía los aportes realizados por el gobierno en cuanto al instrumental que disponía el Instituto. Las contribuciones de entidades privadas también continuaban. En este año la Fundación Emilio Ocampo distribuyó 280 millones de pesos entre la Cátedra de Microbiología UBA, los Institutos Malbrán y de Pergamino, la Facultad de Ciencias Exactas y Naturales UBA, las Universidades de La Plata y Córdoba, y los Institutos de Investigaciones Médicas y Nacional de Investigaciones de Ciencias Naturales. ${ }^{75}$

En el Instituto Malbrán también continuaban los trabajos vinculados con la enfermedad desarrollando un programa para completar el conocimiento sobre la estructura y replicación del virus Junín con el objetivo final de disponer de un antígeno vacunante. Los Dres. Zulema Martínez Segovia y Alberto Pfeifer eran los principales investigadores que llevaban adelante estas pesquisas. ${ }^{76}$

En 1982, últimos tiempos del gobierno de facto, el convenio ARG/78/009 quedó suspendido. Barrera Oro fue contratado por el Instituto Salk en donde continuó desarrollando la vacuna por interés del Ejército norteamericano. A mediados de este año el Instituto dirigido por el Dr. Julio Maiztegui fue distinguido por la Fundación Cargil que le otorgó el premio Ingeniero Agrónomo Antonio E. Marino en una ceremonia en la que se destacó la presencia de una figura señera de la investigación científica médica argentina como lo era el Dr. Federico Leloir. ${ }^{77}$

Octubre de 1983 señala un tiempo clave en la Historia Argentina pues tuvo lugar el restablecimiento del sistema democrático.

El estado de la ciencia [...] era crítico. De hecho, sólo habían sobrevivido unos pocos equipos de investigación científica de buen nivel, entre ellos el que lideraba el premio nobel Dr. Leloir en la Fundación Campomar, el que seguía el Dr. Paladín en la Facultad de Farmacia y Bioquímica, un puñado de buenos físicos en la Comisión Nacional de Energía Atómica y un par de grupos dedicados a la biología molecular y a la microbiología, ${ }^{78}$ 
En éste último campo los discípulos del Dr. Parodi en la Cátedra de la Facultad de Medicina de la UBA. Y, también continuaba el Instituto de Pergamino liderado por Julio Maiztegui.

Este fundamental cambio político, sin embargo, significó la interrupción de las obras del laboratorio que se construía en Pergamino. El desarrollo económico y el científico enfrentaron graves dificultades debido al peso de la deuda externa que agobiaba al país. El Dr. Maiztegui logró la renovación del convenio pero sin que esto implicara alguna erogación por parte del Estado argentino. No obstante esta situación, si analizamos el presupuesto destinado a los Institutos estatales de Investigación observamos que el Instituto de Pergamino recibió, en 1983, 11.689.400 pesos, ocupando, en cuanto a monto percibido, el segundo lugar luego del Instituto Malbrán. ${ }^{79}$

Entretanto, el Dr. Barrera Oro, en 1984, había logrado una vacuna a la que denominó Candid I porque, como el mismo científico explicó, "Candid en inglés significa pura, [... . sin propósitos secundarios, sólo con el propósito de proteger, de ayudar un poco a la gente de la zona". Luego de las pruebas en animales, se inoculó a los primeros voluntarios, en total 92, que fueron soldados norteamericanos El 20 de diciembre de 1986 fueron inoculados los primeros catorce voluntarios del área de Pergamino. El primero de éstos fue el mismo Maiztegui. La fecha elegida para el inicio de este estudio fue una decisión de Barrera Oro pues un 20 de diciembre pero de 1958 este investigador resolvió autoinocularse el virus Junín para cumplimentar el último de los postulados de Koch y terminar con las discusiones que se habían suscitado sobre el agente etiológico de la FHA. Entre 1986 y 1988 se inocularon más de 300 voluntarios humanos del área de Pergamino, experiencia a cargo del grupo dirigido por el Dr. Maiztegui, en la que no se observaron efectos clínicos adversos y, en más del $90 \%$ se detectaron anticuerpos contra el virus Junín.

Para llevar a cabo el estudio de la efectividad e inocuidad de la vacuna a campo abierto, último paso para poder implementar una vacunación masiva, se seleccionaron 41 localidades del sur de la provincia de Santa Fe donde se había verificado una alta incidencia de la enfermedad. ${ }^{80}$ Se inoculó un total de 5927 voluntarios de sexo masculino de 15 a 60 años que trabajaban o residían en la zona rural. Este estudio se realizó en forma prospectiva, a doble ciego, es decir, se inoculó el $50 \%$ de los voluntarios con la vacuna y el $50 \%$ restante con una sustancia control. ${ }^{81} \mathrm{~A}$ fines de 1990 Maiztegui y Barrera Oro pudieron comprobar en Estados Unidos, al romper los sellos de control de los pacientes y voluntarios inoculados, el 95,5\% de efectividad de la Candid I, ${ }^{82}$ inscribiendo así, una nueva página en la historia de la ciencia argentina, al lograr desarrollar una vacuna, conforme a las normas científicas internacionales, que cumple o excede los requisitos para las vacunas vivas atenuadas como el sarampión, paperas, y poliomielitis. A pesar de este logro, once años después de lo previsto (1982) aún restaban finalizar las obras del laboratorio que permitirían producir la vacuna en el país.

También en este período destacan los aportes del grupo dirigido por la Dra. Marta Sabattini. Esta doctora en Bioquímica, egresada de la Universidad Nacional de Rosario, se había especializado en virus transmitidos por artrópodos (Arbovirus) en Belem (Brasil) con una beca de la Fundación Rockefeller. En 1964 se incorporó al Instituto de Virología de la Universidad Nacional de Córdoba donde comenzó a organizar un equipo dedicado al estudio de los Arbovirus. Debido a su designación como representante del Instituto ante la Comisión Nacional Coordinadora orientó a su grupo hacia la investigación en FHA ${ }^{83}$ Con aportes de este organismo instalaron una estación de campo permanente para la recolección de muestras en la zona afectada. ${ }^{84}$ Durante treinta años, de manera continua, realizaron trabajos sobre la enfermedad, fundamentalmente la vigilancia epidemiológica de la virosis. La Dra. Sabattini, personalmente, se contactaba con cada nuevo Ministro de Salud, con cada nuevo Jefe de Epidemiología y con los médicos de la zona epidémica, logrando así la notificación de todos los casos. Este equipo también desarrolló importantes estudios ecológicos que permitieron establecer fehacientemente los reservorios del virus Junín, agente etiológico de la FHA. ${ }^{85}$

\section{Conclusión}

A pesar de la alternancia de gobiernos democráticos y de facto, hubo un continuo interés del Estado nacional en la cuestión de la fiebre hemorrágica, demostrado en la permanencia de la Comisión Nacional Coordinadora a lo largo del 
período 1964-1978 y en el hecho que, cuando cesó en sus funciones, fue porque se la reemplazó con la creación de un Instituto y un Programa Nacional. Seguramente en este interés estatal incidió el impacto económico de la enfermedad al afectar al hombre de campo en tiempos de cosecha en la región pampeana.

El interés del Estado, a su vez, garantizó la continuidad de los trabajos científicos al posibilitar contar con recursos, si bien con numerosas y habituales dificultades y muy alejado de lo ideal, a través de la mencionada Comisión Nacional Coordinadora y del CONICET. Sin embargo, en esta característica, no podemos ignorar el peso de la decisión y afán personal de los investigadores y la consistente formación según el modelo de Bernardo Houssay, todas circunstancias que contribuyeron a la concreción de sólidos y fundamentales avances en orden al conocimiento científico sobre la virosis. Destacan también los aportes económicos realizados en este sentido por la Fundación Emilio Ocampo a partir de 1965. La Comisión Nacional, además, vehiculizó el intercambio de información entre los distintos equipos científicos, circunstancia muy diferente en relación al período 1958-1962.

Numerosas publicaciones científicas dan testimonio de los trabajos realizados por la Comisión de la Facultad de Medicina de la Universidad de Buenos Aires en el período 1963-90. Este grupo tuvo como ámbito de trabajo una Cátedra que significó, por un lado, la imposibilidad de dedicación exclusiva a las tareas de investigación y, al mismo tiempo, la no subordinación a determinadas políticas científicas e inestabilidad institucional como había ocurrido con el equipo dirigido por el Dr. Ignacio Pirosky.

En el caso de la fiebre hemorrágica argentina, una enfermedad a virus, resultaba fundamental el hallazgo de una vacuna que posibilitaría erradicarla o controlarla. Cabe preguntarse si la decisión de intentar desarrollar una vacuna en 1968 era la más adecuada ya que en el país no estaban dadas las condiciones para un proyecto de tal envergadura. Sin embargo ipuede un investigador ante la oportunidad de concretar un hecho científico trascendente, como lo es una vacuna, negarse a tal intento? La zona epidémica, como dijimos de gran importancia económica para el país, se había ampliado en pocos años, poniendo en riesgo a un número cada vez mayor de personas. También debemos considerar que tal logro indudablemente otorgaría al grupo, como a cada uno de sus miembros, la superioridad en orden a los trabajos de investigación que se desarrollaban sobre fiebre hemorrágica argentina. Así el interés por realizar un importante aporte al conocimiento científico, por proporcionar una solución definitiva a un significativo problema sanitario argentino como el de asegurar un superior posicionamiento en relación a los pares confluyeron en la decisión del Dr. Parodi que se cristalizó con el desarrollo de la vacuna XJ Clon 3. El no cumplimiento de los requisitos establecidos por la Organización Mundial de la Salud fue la razón científica que se esgrimió para detener los planes de vacunación. Decisión sustentada en un dictamen de la Comisión Nacional Coordinadora y de la Academia Nacional de Medicina. Dictámenes que destacaron la labor del equipo del Dr. Parodi y avalaron la decisión de iniciar una vacunación experimental.

La competitividad característica en los ámbitos científico-intelectuales se manifestó de manera evidente entre los grupos que trabajaron con esta enfermedad. La punga entre el equipo dirigido por el Dr. Armando Parodi con el liderado por el Dr. Ignacio Pirosky de la primera etapa (1958-1963) fue suplantando por la rivalidad entre el grupo de Parodi con el dirigido por el Dr. Maiztegui durante el segundo período.

El equipo dirigido por Julio Maiztegui desarrolló fundados trabajos de investigación; cabe mencionar como jalones fundamentales la demostración de la utilidad del plasma de convaleciente como tratamiento específico (1974-1978) y la visualización del virus Junín en seres humanos (1974). El centro de Pergamino logró desarrollarse como ámbito de investigación, tratamiento y prevención, articulando los trabajos científicos con los médicos de la región. Así, logró, con la colaboración de estos profesionales, implementar la vigilancia epidemiológica de la enfermedad.

Finalmente este grupo logró imponerse en el campo de la fiebre hemorrágica cuando se convirtió en Instituto Nacional, en sede de un Programa Nacional de prevención y con la firma del convenio internacional (ARG/78/009) que posibilitó el desarrollo de la vacuna Candid I. Diversos factores incidieron en este proceso: indudablemente tuvieron peso los logros científicos del equipo de Pergamino; pero seguramente también influyeron la capacidad de liderazgo y gestión del Dr. Maiztegui, quien además se desempeñó como Coordinador de Zona Sanitaria desde 1976; también la suspensión de la vacuna XJ Clon 3; la fortuita circunstancia de amistad personal entre el Dr. Julio Barrera Oro y el 
Capitán Adolfo Maillé, Subsecretario de Estado de Medicina y Sanitaria; y el interés de Estados Unidos en la vacuna por cuestiones de guerra bacteriológica coincidentemente con la presencia de un gobierno militar en nuestro país que no pondría reparos.

La figura de Julio Maiztegui se destaca por haber logrado la creación de un Instituto Nacional en plena zona epidémica, de un Programa Nacional de Prevención y Lucha y, como hemos señalado, la firma del convenio ARG/78/009 que posibilitó la construcción de un laboratorio de Alta Seguridad para producir vacunas.

Meritoriamente se reconoce el logro científico de la vacuna Candid I a los Dres. Maiztegui y Julio Barrera Oro, quien la desarrolló. No obstante, los avances científicos son la resultante de intentos - acertados y fallidos -, experiencias y conocimientos previos. Así, consideramos que sin los estudios y proyectos precedentes, particularmente los aportes de la Comisión Nacional Ad Hoc, bajo la dirección del Dr. Ignacio Piroksy, y los de la Comisión de la Facultad de Medicina de la UBA, dirigida por el Dr. Armando Parodi, particularmente los trabajos vinculados con la vacuna XJ Clon 3, la Candid no hubiera sido posible. También deben ser destacados los valiosos aportes del Instituto de Virología de Córdoba bajo la dirección de la Dra. Marta Sabattini.

\section{Extensión progresiva del área endémica de la fiebre hemorrágica argentina}

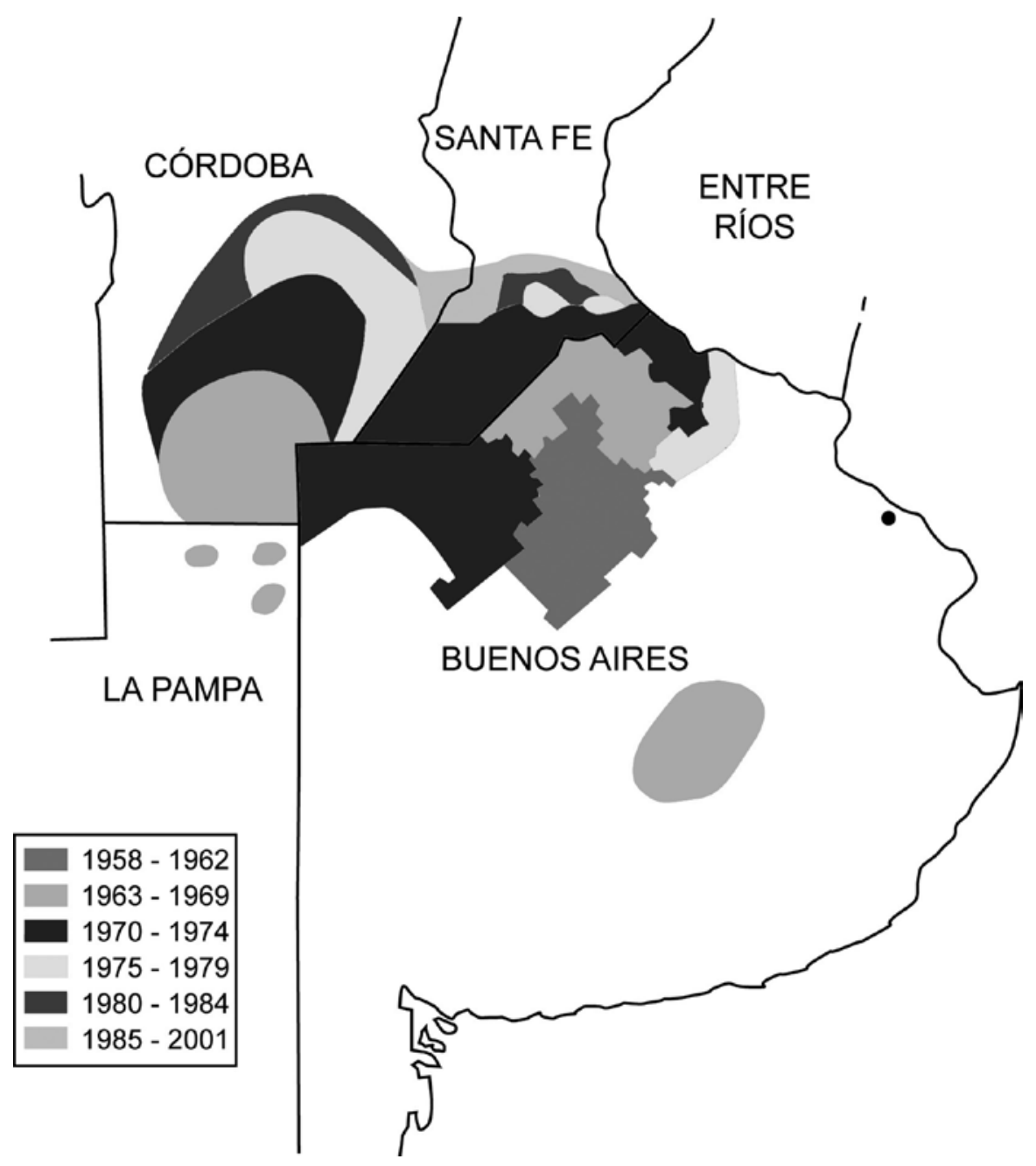




\section{Notas e referências bibliográficas}

Graciela Agnese es doctora en Historia por la Facultad de Medicina de la Universidad de Buenos Aires e investigadora del Instituto de Historia de la Facultad de Derecho y Ciencias Sociales de Rosario de la Pontificia Universidad Católica Argentina. E-mail: gagnese@arnet.com.ar.

1 La denominación de fiebre hemorrágica argentina corresponde al Dr. Humberto Rugiero, aludiendo a sus síntomas característicos como fiebre y una tendencia a las hemorragias y a que se localiza únicamente en nuestro país.

2 PIROSKY, Ignacio; ZUCCARINI, Juan; MOLINELLI WELLS, Ernesto; BARRERA ORO, Julio; MARTINI, Pedro; COPELLO; Andrés; Virosis hemorrágica del Noroeste Bonaerense. Buenos Aires: Instituto Nacional de Microbiología, 1959. p. 15. MARTínEZ PINTOS, Ismael. Mal de los rastrojos - Fiebre hemorrágica epidémica del noroeste de la Provincia de Buenos Aires. La Plata: Comisión de Investigación Científica, 1960. p. 27.

3 El equipo estaba integrado por los doctores Ernesto Molinelli Wells; Juan Zuccarini; Arturo Di Pietro Pedro Martini; Julio Barrera Oro; Alberto Pfeifer; Lidia Martos y Matilde. D’Empaire y el técnico Luis Gutman Frugone.

4 Este "team" científico estaba conformado por los Dres. Marcelo Frigerio - bacteriología; Norma E. Metler - virología; Félix Garzón, Marta Boxaca - virología; Lucía de Guerrero, Nora R. Nota - bacteriología; Enrique Rivero - patología y José María de la Barrera - entomología; todos miembros de la cátedra de Parasitología y Microbiología. Y por los Dres. Laura Astarloa; Carlos González Cambaceres; Francisco Maglio; Guido Squassi; Enrique Libonatti; Diana Fernández y la Dra. Giacosa. Este fue el primer grupo científico en iniciar trabajos de investigación vinculados con la fiebre hemorrágica argentina

5 REIG, Osvaldo. Excelencia y atraso. Buenos Aires: Ediciones de la Flor, 1992. p. 13.

6 Sobre los trabajos científicos del período 1958-1961, véase AGNESE, Graciela. Primeros investigadores de la fiebre hemorrágica argentina 1953-1963. Buenos Aires: Academia Nacional de la Historia, 2003.

7 Cooperativas agrícolas: que representaban a pequeños y medianos productores agropecuarios.

8 Sociedad Rural Argentina: entidad que representa al sector agrario latifundista.

$9 \quad$ La Razón, Chivilcoy, p. 1, 4 de julio de 1962.

10 Testimonio oral de la Dra. Marta Sabattini. Virus Junín en la Provincia de Córdoba. In: Comisión Nacional Coordinadora para el Estudio y Lucha contra la FHA. Buenos Aires, Secretaría de la Comisión Nacional para el Estudio y Lucha contra la FHA, 1966, p. 85-87.

11 Testimonio oral de la Dra. Marta Sabattini. Virus Junín en la Provincia de Córdoba, Instituto de Virología de Córdoba. In: Comisión Nacional Coordinadora para el Estudio y Lucha contra la FHA, op. cit., 1966, p. 85-87.

12 Primera Plana, Buenos Aires, p. 29, 18 de junio de 1963.

13 La Nación, Buenos Aires, p. 6, 5 de agosto de 1962.

14 La Razón, Buenos Aires, p. 4, 19 de agosto de 1963.

15 El 8 de junio de 1958, bajo iniciativa del Círculo Médico de Junín, y por decisión del Dr. Rodolfo Weskamp Irigoyen, director del Hospital Regional, se habilitó una sala especial destinada a la investigación y tratamiento, que se convertiría en el Centro de Investigación y tratamiento de la fiebre hemorrágica argentina en el que se desempeñaron, bajo la dirección del Dr. Héctor A. Ruggiero, los doctores Alberto Cintora y Clemente Magnoni, a cargo del pabellón de emergencia, Fernando Pérez Izquierdo, integrante del cuerpo médico, y el bioquímico Héctor Antonio Milani, jefe de Laboratorio. Este Centro fue el organismo de mayor envergadura abocado, especialmente, al tratamiento de los enfermos y a la prevención durante el período 1958-1962.

16 MARTíNEZ PINTOS, op, cit., 1960, p. 114. ALVAREZ AMBROSETTI, Enrique; CINTORA, Alberto; LOCÍCERO, Rosario; MAGNONI, Clemente; MILANI, Héctor A; VACCAREZA, Raúl. Observaciones Clínicas. El Día Médico, Buenos Aires, La Técnica Impresora, n. 10, p. 234, 1959. MARTíNEZ PINTO, Ismael; GUARINO, Héctor; CZEPLOWODSKI, León; MOLTENI, Horacio; PETRILLO, Carlos; NELLY, Santiago; JARCHELS, Friedolin. Nuestra experiencia en el tratamiento del "mal de los rastrojos". La Semana Médica, Buenos Aires, t. 118, n. 21, p. 856, 24 de abril de 1961.

17 MARTÍNEZ PINTOS, op. cit., 1960, p. 27.

18 Los médicos de Junín justificaban la terapéutica que habían adoptado y difundido con aprobación del Ministerio de Salud de la Provincia de Buenos Aires, sosteniendo que se trataba de donantes del ámbito rural, caracterizados por la buena salud; por otro lado, confiaban en la certeza de sus diagnósticos sustentados en la experiencia que tenían en tratar este tipo de enfermos, confiando en su "ojo clínico".

19 Citamos algunas de las ponencias: PARODI; FRIGERIO; NOTA; NEJAMKIS; DE GUERRERO; LUCÍA B; BISSO. Inhibición de la respuesta inmunológica secundaria en la fiebre hemorrágica experimental (virus Junín), p. 137-139; PARODI; BOXACA; COTO; GONZÁLEZ. Inactivación del virus Junín (fiebre hemorrágica argentina, Cepa XJ) por la radiación ultravioleta, p. 339; BOXACA; COTO; PARODI, GONZÁLEZ. Efecto del PH y de la temperatura sobre el virus Junín (fiebre hemorrágica argentina, Cepa XJ), p. 339; Sétimo Congreso Internacional de Medicina Tropical e Malaria, Rio de Janeiro, 1 al 11 de septiembre de 1963.

20 La Razón, Buenos Aires, p. 7, 28 de febrero de 1964.; La Razón, Buenos Aires, 5 de abril de 1964. p. 5.

21 nforme Preliminar de la Comisión Nacional Coordinadora para el Estudio y Lucha contra la FHA, Buenos Aires, Secretaría de la Comisión Nacional de Estudio y Lucha contra la FHA, 1966. p. 10.

22 La Razón, Buenos Aires, p. 3, 24 de marzo de 1964.

23 Los jornaleros procedían de provincias del Norte del país como Santiago del Estero, Misiones, Corrientes; y también de países limítrofes como Bolivia, Paraguay y Chile.

24 Diario de Sesiones de la Cámara de Diputados - Congreso Nacional, año 1964, Sesiones ordinarias (del 27 de abril al 29 de mayo de 1964. Buenos Aires: Imprenta del Congreso de la Nación, 1965. p. 12.

25 Estas eran la Facultad de Medicina de la Universidad de Buenos Aires - Cátedra de Microbiología y Parasitología y Cátedra de Enfermedades Infecciosas -, Facultad de Medicina de la Universidad del Salvador, Instituto de Virología de la Universidad Nacional de Córdoba, Facultad de Ciencias Médicas de la Universidad Nacional del Litoral, Universidad Nacional del Nordeste - Facultad de Medicina de Corrientes -, Museo Argentino de Ciencias Naturales "Bernardino Rivadavia" y Comando de Sanidad del Ejército. 
Testimonio oral de la Dra. Marta Sabattini investigadora a cargo de los trabajos de investigación sobre FHA en el Instituto de Virología de la Universidad Nacional de Córdoba desde 1965; y del Dr. Julio Barrera Oro miembro de la Comisión Nacional dirigida por el Dr. Pirosky, investigador de FHA en el Instituto Malbrán desde 1958.

27 La Opinión, 27 de diciembre, Pergamino, p. 9, 1964.

28 VANELLA, José María. Epidemiología de la fiebre hemorrágica argentina (Conferencia). In: La Semana Médica. Buenos Aires, p. 1503, 19 de octubre de 1964.

29 Palabras del Dr. Houssay durante la clausura de la IV Reunión Conjunta de Comisiones Asesoras y Regionales del CONICET (La Razón, Buenos Aires, p. 4 , 10 de mayo de 1964).

30 Este proyecto tiene reminiscencias de la M.E.P.R.A, Misión de Estudios de Patología Regional Argentina, creada por el Dr. Salvador Mazza, en Jujuy en 1928, desde donde educó a médicos, maestros, enfermeros y público en general en la detección de enfermedades infecciosas, fundamentalmente el mal de Chagas, comprometiéndolos como agentes sanitarios y pudiendo llevar un registro de casos.

31 Testimonio oral del Dr. Julio Barrera Oro.

32 Esta fundación había sido creada por el Dr. Narciso Ocampo en honor a su hijo muerto en el brote epidémico del '64, con el objetivo de promover trabajos de investigación sobre FHA.

33 VILCHES, Antonio. Investigaciones sobre FHA del Instituto Nacional de Microbiología. In: Informe Preliminar de la Comisión Nacional Coordinadora para el Estudio y Lucha contra la FHA, op. cit.,1966, p. 77 y 78.

34 VILCHES, op. cit., p. 79 y 85.

35 Investigaciones sobre fiebre hemorrágica argentina del Instituto Nacional de Microbiología. Comisión Nacional Coordinadora para el Estudio y Lucha contra la FHA, op. cit., 1966, p. 78-84.

36 Revista de la Asociación Médica Argentina, Buenos Aires, v. 78, n. 5, p. 221-226, 1964; n. 6, p. 281-293, 1964; n. 7, p. 360-374, 1964; n. 9, p. 500-510, 1964; n. 511, p. 611-618, 1964; v. 79, n. 4, p. 155, 1965; n. 11, p. 536, 1965; v. 80, p. 490, 1966; v. 81, n. 2, p. 7, 1967. La Prensa Médica Argentina, Buenos Aires, v. 51, n. 20, p. 10-19, 139-142, 169-173, 195-198, 239-242, 1964, donde se publicaron los trabajos que la cátedra presentó en el $8^{\circ}$ Congreso Internacional de Medicina Interna, Buenos Aires, noviembre de 1964; Segundas Jornadas Entomoepidemiológicas Argentina. El Día Médico, Buenos Aires, n. 21, año XXXIX, 1967.

37 El Día Médico, Buenos Aires, n. 10, 1964; Medicina, Buenos Aires, v. XXIV, n. 3; Sociedad Argentina de Investigación Clínica, n. 45, 1964; Ciencia e Investigación, Buenos Aires, Asociación Argentina para el Progreso de la Ciencia, t. 21, n. 3, 1965; Revista de la Asociación Médica Argentina, Buenos Aires, v. 79, n. 5, 1965; n. 6, 1965; La Prensa Médica Argentina, Buenos Aires, v. 52, n. 24, 1965.

38 CONICET: organismo del Estado creado bajo impulso del Dr. Bernardo Houssay el 5 de febrero de 1958 para promover el desarrollo científico.

39 Memoria de la Academia Nacional de Medicina año 1967. Buenos Aires: Academia Nacional de Medicina, p. 5.

40 BARRERA ORO, JG; GIOROLA, RA; GUTMAN FRUGONE, L. Estudios Inmunológicos con virus Junín II. Inmunidad adquirida por cobayos inoculados con virus inactivado por formol. Medicina, Buenos Aires, Sociedad Argentina de Investigación Clínica, v. 37, n. 5, 1967.

41 RUGIERO, Humberto; ASTARLOA E; RUGGIERO, Héctor; ASTARLOA, LN; GHIGLIAZZA, H; GONZÁLEZ CAMBACERES, C; MAGLIO; SQUASSI, G. Fiebre Hemorrágica Argentina - Inoculación accidental y consideraciones médico-legales. Revista de la Asociación Médica Argentina, Buenos Aires, v. 79, n. 11, p. 536 y $537,1965$.

42 Citamos algunas de las publicaciones: PARODI, Armando; RUGIERO, Humberto. Fiebre hemorrágica epidémica: infección de laboratorio. Asociación Médica Argentina, Buenos Aires, n. 9, 1962; RUGIERO, Humberto; PARODI, Armando; RUGGIERO, Héctor, METLER, Norma; BOXACA, Marta; GUERRERO, Lucía Barcelona de; CINTORA, Alberto; MAGNONI, Clemente; MILANI, Héctor; MAGLIO, Francisco; GONZÁLEZ CAMBACERES, Carlos; ASTARLOA, Laura; SQUASSI, Guido; FERNÁNDEZ, Daniel; GIACOSA; A. Fiebre hemorrágica argentina - período de incubación e invasión. Revista de la Asociación Médica Argentina, Buenos Aires, v. 78, n. 5, 1964; PARODI; BARCELONA, Lucía de. Fiebre hemorrágica experimental en cobayos. Revista de la Asociación Médica Argentina, Buenos Aires, n. 6, 1965; PARODI; METLER. Estudio serológico de la epidemia de FHA del año 1963. La Prensa Médica Argentina, Buenos Aires, t. 52, n. 24, 1965; PARODI; ADLER. Relaciones antigénicas entre siete cepas de virus Junín. Revista de la Sociedad Argentina de Biología, Buenos Aires, t. 41, n. 1-4, 1965; PARODI; RAMAZO. Fiebre hemorrágica experimental. Glucemia. Revista de la Sociedad Argentina de Biología, Buenos Aires, t. 42, n. 5-8, 1966; PARODI; RUGIERO. Fiebre hemorrágica argentina, diferentes vías de contagio accidental. El Día Médico, Buenos Aires, n. 21; PARODI; WEISSEMBACHER. Acción de los inmunosueros en la Fiebre Hemorrágica experimental. Medicina, Buenos Aires, t. 28, n. 2, 1968; PARODI; GUERRERO. Tamaño del virus Junín. Revista de la Sociedad Argentina de Biología, Buenos Aires, t. 44, n. 1-4, 1968.

43 Fiebre Hemorrágica Argentina (Folleto), Buenos Aires, Programa Nacional de Lucha contra la FHA - Ministerio de Salud y Acción Social de la Nación, 1987.

44 Resolución n. 4395/67, expediente 28.427/67. In KRALY, Rita de. Trabajo de recopilación, Archivo del Instituto Nacional de Enfermedades Virales Humanas, "Dr. Julio I. Maiztegui" (INEVH).

45 Cepa XJ Clon 3 "obtenida con clonado de la cepa prototipo XJ, a partir de un pasaje alto en cerebro de ratón utilizando como sustrato una línea continua de células de riñón de conejo", FRIGERIO, Marcelo. Prevención de la FHA. Ciencia e Investigación, Buenos Aires, t. 33, p. 268, 1977.

46 GUERRERO, Lucía B de; WEISSENBACHER, Mercedes; PARODI, AS. Inmunización contra la FHA con una cepa atenuada de virus Junín. I. Estudio de una cepa modificada del virus Junín - Inmunización en cobayos. Medicina, Buenos Aires: Sociedad Argentina de Investigación Clínica, v. XXIV, n. 1, 1969.

47 RUGGIERO, Héctor; MAGNONI, Clemente; NOTA, Nora; MILANI, Héctor A; PÉREZ IZOUIERDO, Fernando; MAGLIO, Francisco; ASTARLOA, Laura; GONZÁLEZ CAMBACERES, Carlos; MILANI, Héctor Luis. Fiebre hemorrágica argentina. Buenos Aires: El Ateneo, 1982. p. 4. PÉREZ IZOUIERDO. Reseña Histórica de FHA (ponencia). Jornadas sobre Fiebre Hemorrágica Argentina, Laboulaye (Córdoba - Argentina), 1970.

48 FRIGERIO, op. cit., 1977, p. 269.

49 Dictamen de la Academia Nacional de Medicina, 30 de octubre de 1973. Archivo del Instituto Nacional de Enfermedades Virales Humanas "Dr. Julio Maiztegui" (INEVH). Informe del grupo de trabajo designado para evaluar las acciones desarrolladas en nuestro país en la búsqueda de un antígeno específico contra la Fiebre Hemorrágica Argentina. Buenos Aires, 1973. Archivo del INEVH. 
50 RUGGIERO, Héctor; MAGNONI, Clemente; GUERRERO, Lucía B. de; MILANI, Héctor A; PÉREZ IZQUIERDO, Fernando; MILANI, Héctor L. Evolución alejada de vacunados contra la fiebre hemorrágica argentina con la cepa atenuada XJ Clon 3. Estudio clínico, humoral e inmunológico 7 a 9 años después de su inoculación, s/otros datos.

51 También investigaban sobre FHA en el Malbrán Silvia Bendersky, María Berria, Alberto Díaz, Luis Gutman Frugone, Eduardo Lascano, Zulema Martínez Segovia, María Inés de Mitri, Angélica Teyssie, y B. Ayerra de Holstein.

52 En el CEMIC investigaban sobre FHA los Dres. B Elsner, 0 Mandó, E Schwarz.

53 Estos científicos eran Laura Astarloa, Santiago Besuschio, GM Bisso, Marta Boxaca, Guadalupe Carbalall, Carlos González Cambaceres, Celia Coto, Daniel Fernández, Diana Fernández, Marcelo Frigerio 0, Giovanniello, Lucía B de Guerrero, Guillermina Helps, Francisco Maglio, Marta Nejamkis, Nora Nota, Guiso Squassi, Licia Tkaczveski y Mercedes Weissennbacher.

54 BOXACA; SAVY; GIOVANNIELLO. Células Vero persistentemente infectadas con virus Junín. I Comportamiento de la línea Vero frente a la sobreinfección con dos cepas del virus Junín. Medicina, Buenos Aires: Sociedad Argentina de Investigación Clínica, v. 32, n. 3, p. 269-279, 1972.

55 Premio Mariano R. Castex a los Dres. SCHWARZ, ER; MANDÓ, OG; MAIZTEGUI, Jl; VILCHES, AM; OTERO, Elena R. y BERRUTI, Zamira, por Alteraciones en la coagulación de la FHA. Medicina, Buenos Aires: Sociedad Argentina de Investigación Clínica, v. 32, n. 3, p. 247-259, 1972.

56 Memoria de la Academia Nacional de Medicina año 1972. Buenos Aires: Academia Nacional de Medicina, p. 7 y 8.

57 RUGGIERO, Héctor; MAGNONI, Clemente; MILANI, Héctor A; CINTORA, Alberto; PÉREZ IZQUIERDO, Fernando. Tratamiento de la FHA con plasma de convaleciente. La Prensa Médica Argentina, Buenos Aires, v. 59, n. 42, p. 1578, 1972.

58 Fiebre Hemorrágica Argentina (Folleto). Pergamino. Programa Nacional de Lucha contra la FHA Ministerio de Salud y Acción Social de la Nación, Secretaría de Salud, 1987. p. 11.

59 MAIZTEGUI, J. I.; LAGUENS, R. P.; COSSIO, P. M.; CASANOVA, M. B.; DE LA VEGA, M. T.; RITACCO; SEGAL, A; FERNÁNDEZ, N. J.; ARANA, R. M. Observaciones ultraestructurales e inmunohistoquímicas en 4 casos de fiebre hemorrágica argentina. Medicina, Buenos Aires, Sociedad Argentina de Investigación Clínica, v. XXXIV, n. 3, 1974.

60 Boletín de la Academia Nacional de Medicina, Buenos Aires, v. 52, p. 362,1974.

61 REIG, op. cit., 1992, p. 29.

62 NUÑEZ, Sergio; ORIONE, Julio. Disparen contra la ciencia, de sarmiento a Menem, nacimiento y destrucción del proyecto científico argentino. Buenos Aires: Espasa-Calpe, 1995. p. 137.

63 Ibid., p. 28 y 29.

64 MAIZTEGUI, Julio. Epidemiología de la fiebre hemorrágica argentina. Ciencia e Investigación, Buenos Aires, t. 33, p. 361, 1977.

65 GUERRERO, Lucía Barcelona de. Fiebre hemorrágica argentina. Anales de la Academia de Ciencias Exactas, Físicas y Naturales, Buenos Aires, t. 29, p. 228, 1977.

66 Testimonio oral de los Dres. Marta Sabattini y Julio Barrera Oro.

67 Testimonio oral del Dr. Julio Barrera Oro.

68 CUETO, Marcos. El valor de la salud - Historia de la OPS. Washington, OPS, 2004.

69 MAIZTEGUI, Julio; FERNÁNDEZ, Néstor; DAMILANO, Alba J. de. Efficacy of inmune Plasma. In treatment of Argentine Hemorrhagic Fever and association between treatment and a late neurological syndrome. The Lancet, Londres: The Lancet Publishing Group, 1979.

70 Testimonio oral de la Dra. Delia Enría quien ingresó en el INEVH, en 1979, como médica ad honorem. Es la actual Directora del Instituto Nacional de Enfermedades Virales Humanas "Dr. Julio I Maiztegui".

71 Testimonio oral de la Dra. Marta Sabattini.

72 La Opinión. Pergamino, 2 de septiembre de 1980. p. 10, entrevista a las Dras. Nota y Lucía Barcelona de Guerrero.

73 RUGGIERO, Héctor; MAGNONI, Clemente; GUERRERO, Lucía B.; MILANI, Héctor A.; PÉREZ IZQUIERDO, Fernando; MILANI, Héctor L., op. cit., s/otros datos, Archivo personal del Dr. Héctor A. Milani.

74 En 1977 el total de casos había sido de 432, en 1978 de 191, en 1979 de 123 y en 1980 de 80, Informe / Reunión Anual del Programa Nacional de Lucha contra la FHA. Pergamino: INEVH, p. 2 y 3, Archivo del INEVH.

75 La Opinión. Pergamino, p. 5, 25 de junio de 1981. La Razón, Buenos Aires, p. 5, 24 de noviembre de1981.

76 Decreto n. 1088 del Ministerio de Salud Pública y Medioambiente, 4 de noviembre de 1981, aprobando el programa presentado por el Departamento de Virus del Instituto Malbrán.

77 El Dr. Federico Leloir, discípulo de Bernardo Houssay, había sido reconocido con el premio Nobel de Química en 1970.

78 REIG, op. cit., 1992, p. 59

79 Crédito Presupuestario. Año 1983, Archivo del INEVH.

80 Estas localidades eran: San José de la Esquina, Arequito, Los Molinos, Casilda, Pujato, Berabevú, Los Quirquinchos, Cañada de Ucle, Villada, Chabás, Sanford, Fuente, Chovet, Firmat, Bombal, Bigand, Villa Mugueta, Arminda, Acebal, Miguel Torres, Carreras, Alcorta, Máximo Paz, Pavón Arriba, Uranga, Labordeboy, Hughes, Rueda, Cepeda, Godoy, JB Molina, Sargento Cabral, Peyrano, Cañada Rica y General Nelly.

81 Nota enviada al Director Nacional de Institutos e Investigación Dr. Luis Pedro Mujica del Ministerio de Salud y Acción Social de la Nación por el Dr. Julio Maiztegui como Director del Instituto de Pergamino: Archivo del INEVH.

82 La vacuna contra la fiebre hemorrágica argentina - Información para profesionales (Folleto). Pergamino: Instituto Nacional de Enfermedades Virales Humanas, Ministerio de Salud y Acción Social de la Nación, 1994.

83 Este grupo estaba conformado por los Dres. Lola González -Sección Aislamiento -, Juan Carlos Fain Binda - epidemiólogo -, la bióloga Beatriz Rosso de Ferradás - estudios de ácaros - los señores Raúl Vega -jefe de trabajos de campo -, Gladis Díaz y Anita Sánchez - Laboratorio de Serología - entre otros 
auxiliares. Y, también el Dr. Jorge Crespo del Museo Argentino de Ciencias Naturales, quien asesoraba sobre los trabajos con roedores; posteriormente se incorporaría la Dra. Marta Contigiani. Testimonio oral de la Dra. Marta Sabattini. FAIN BINDA, Juan Carlos. El mal salió del rastrojo. Historia de una enfermedad, su tiempo y su gente, Rosario: Universidad Nacional de Rosario, 2003. p. 163.

84 VIRUS Junín en la provincia de Córdoba, op. cit., 1966, p. 5 y 86.

85 Los roedores de la especie Calomys musculinus, Calomys laucha y Akodon azarae. Estos trabajos fueron realizados con el asesoramiento del Dr. Crespo, en ese entonces Director del Museo de Ciencias Naturales de Buenos Aires, Argentina.

[Recebido em outubro de 2011, aprovado para publicação em abril de 2012] 